\title{
Acute, sub-acute, sub-chronic and chronic toxicity studies of four important Nigerian ethnomedicinal plants in rats
}

\author{
Abdullah M. Tauheed ${ }^{1 *}$ (D, Mohammed Mamman ${ }^{1,2}$, Abubakar Ahmed ${ }^{3}$, Na'imatu A. Sani $^{4}$, \\ Mohammed M. Suleiman ${ }^{1}$, Mohammed H. Sulaiman ${ }^{5}$ and Emmanuel O. Balogun ${ }^{2,6}$
}

\begin{abstract}
Background: Azadirachta indica, Khaya senegalensis, Anogeissus leiocarpus and Tamarindus indica are important ethnomedicinal plants used for health mitigation since the history of mankind. They are used discretionarily in folkloric medicine on the premise that they are natural products devoid of synthetic preservatives. However, nature endows plants with metabolites for warding off potential attacks from animals and the environment. Some of these metabolites are responsible for toxicity of some plants. Furthermore, drug-induced liver injuries and nephrotoxicity are the leading causes of pharmaceutical attrition of promising drug candidates in clinical trials. Thus, we aimed to evaluate the safety of four ethnomedicinal plants in short-, medium- and long-term usage.
\end{abstract}

Methods: Rats dosed once with $5000 \mathrm{mg} / \mathrm{kg}$ extracts of each of these plants served as acute study (AS) while rats dosed daily with $2000 \mathrm{mg} / \mathrm{kg}$ for 2, 12 and 14 weeks served as sub-acute (SAS), sub-chronic (SCS) and chronic (CS) studies, respectively. Rats administered distilled water served as the negative control (NC).

Results: A. leiocarpus and T. indica significantly reduced percentage weight gain in the SCS compared to the NC. A. leiocarpus significantly $(P<0.05)$ increased transaminases and alkaline phosphatase in the AS only; and total protein (TP) in the AS, SAS, SCS and CS compared to the NC. K. senegalensis significantly $(P<0.05)$ increased alanine aminotransferase but significantly $(P<0.05)$ decreased TP in the AS only compared to the NC. However, $A$. indica and $T$. indica significantly $(P<0.05)$ increased globulin and aspartate transaminase in the CS only. Whereas $A$. leiocarpus and $K$. senegalensis significantly $(P<0.05)$ increased urea and creatinine in the AS than SAS, SCS and CS; $\mathrm{Na}^{+}$and $\mathrm{K}^{+}$were significantly higher in the SCS and CS studies compared to the NC. The histological lesions seen ranged from cellular degeneration, congestion, fibrosis to necrosis.

Conclusion: Thus, nonlethal, reversible toxic insults occur in short-term usage (AS); while, insidious lethal toxic effects occur in medium-term (SAS) and long-term usage (SCS and CS). The ability of these plant to maintain adequate hematological parameters, bodyweight and absence of mortality may explain free usage of preparations made from these plants in folkloric medicine.

Keywords: Aminotransferases, Alkaline phosphatase, Clinicopathology, Kidney function test, Organosomatic index, Toxicity studies

\footnotetext{
* Correspondence: mtauheed@abu.edu.ng; amtauheed40@gmail.com ${ }^{1}$ Department of Veterinary Pharmacology and Toxicology, Faculty of Veterinary Medicine, Ahmadu Bello University, Zaria, Kaduna State, Nigeria Full list of author information is available at the end of the article
}

\section{Springer Open}

(c) The Author(s). 2021 Open Access This article is licensed under a Creative Commons Attribution 4.0 International License, which permits use, sharing, adaptation, distribution and reproduction in any medium or format, as long as you give appropriate credit to the original author(s) and the source, provide a link to the Creative Commons licence, and indicate if changes were made. The images or other third party material in this article are included in the article's Creative Commons licence, unless indicated otherwise in a credit line to the material. If material is not included in the article's Creative Commons licence and your intended use is not permitted by statutory regulation or exceeds the permitted use, you will need to obtain permission directly from the copyright holder. To view a copy of this licence, visit http://creativecommons.org/licenses/by/4.0/. 


\section{Background}

Ethnomedicinal plants have been widely used in humans and animals as therapeutic remedies for the treatment, mitigation and prevention of diseases in traditional medicine for centuries in both developed and developing countries. The general perception is that medicinal plants are natural products devoid of synthetic preservatives and therefore, safe for discretional uses. Over 85\% of disease conditions of humans and animals, ranging from bacterial infections to cancer and immunological disorders are treated with either natural products or compounds derived from natural products [1]. Natural medicines are fast becoming mainstay primary healthcare alternatives worldwide, with approximately $50 \%$ of the USA population using natural medicines for the treatment and prevention of ill-health conditions [2]. About $70 \%$ of therapeutic compounds in use today or currently in clinical trials are obtained directly from natural products or synthesized from natural products [1]. This has led to the codification of the natural environment as a rich source of unique biodiversity for pharmaceutical lead-compound identification and drug discovery [3]. The drug discovery process is complicated and interwoven, requiring not only information about pharmacodynamics and pharmacokinetic parameters of the compound but also, more importantly, its safety [4].

Drug-induced liver injury and nephrotoxicity are the leading causes of pharmaceutical withdrawals of promising drug candidates in clinical trials $[5,6]$. Whereas, aminotransferases and to a lesser extent, alkaline phosphatase, sorbitol dehydrogenase, glutamate dehydrogenase, gamma-glutamyltransferase, total bilirubin, total bile acids, and 5'-nucleotidase are the commonly evaluated biomarkers in drug safety assessment of hepatotoxicity; blood urea nitrogen, serum creatinine, sodium and phosphorous are the common endpoint indicators used to evaluate renal function [7]. Therefore, assessment of at least four serum parameters, involving a minimum of two for each of the hepatocellular and hepatobiliary serum biomarkers has been recommended for a safety study of xenobiotics [8]. The high susceptibility of kidneys to xenobiotics may not be unconnected with a copious volume of circulating blood (about 25\% of cardiac output), which contains compounds (xenobiotics) or their metabolites delivered to the kidneys for filtration. Furthermore, the sole responsibility of nephrons in the processes of urine formation aggravates the concentration of toxicants contained in the blood in renal tubular fluid [5]. Although efforts are ongoing to identify specific urinary biomarkers to study the effects of potential drug candidate on kidneys and to monitor renal function with some successes being made, Food and Drug Administration of the United States of America still recommends the use of blood urea nitrogen and serum creatinine in rats as reliable indicators of toxic insult to the kidneys [9].

Azadirachta indica A. Juss. (Maliaceae), Anogeissus leiocarpus (DC.) Guill. \& Perr. (Combretaceae), Khaya senegalensis (Desv.) A. Juss. (Maliaceae), and Tamarindus indica L. (Fabaceae) are important medicinal plants with wide ethnomedicinal and scientifically validated applications. T. indica is used to treat constipation, abdominal pain, wounds, diarrhoea and dysentery, fibril conditions and malaria [10] A. leiocarpus is used to treat tuberculosis, cough, toothache and dental caries, intestinal parasites, fungal infection, wound, malaria, diabetes and viral infections [11]. Similarly, K. senegalensis is reported to be effective against intestinal parasites, bacterial infections, diabetes, helminthosis, cancer and trypanosomiasis [12]. The ethnopharmacological applications of $A$. inidca include management of tuberculosis, malaria, cancer, diarrhoea, gastric ulcer, wound and fungal infection [13]. While medicinal plants are generally regarded as safe medicines with a wide margin of safety, nature has endowed them with metabolites to ward off potential attacks from animals and the environment. These metabolites are responsible for the pigmentation, fragrance and toxicity of some of these plants [14]. Recently, we reported the potential antitrypanosomal effects of stem-bark extracts of $A$. leiocarpus and $K$. senegalensis [15]. It is, therefore, necessary to study their safety margins. Thus, we aim to investigate $A$. indica, $K$. senegalensis, $A$. leiocarpus and $T$. indica for safety in short- (acute), medium- (sub-acute) and long- (subchronic and chronic) term uses in rat.

\section{Materials and methods}

\section{Chemical and reagents}

The chemicals used were analytical grade and include: methanol 99.8\%, hexane $96.0 \%$ and ethyl acetate $99.5 \%$. With the exception of anisaldehyde sulphuric acid which was a general purpose reagent, all other reagents used were laboratory reagents and include: galcia acetic acid, sulphuric acid, acetic acid, chloroform, bismuth subnitrate, distilled water, potassium iodide, alcoholic potassium hydroxide $20 \%$, alcoholic aluminium chloride $2 \%$ and alcoholic ferric chloride $2 \%$.

\section{Plant collection and identification}

The leaves of Azadirachta indica and Tamarindus indica; and stem-barks of Anogeissus leiocarpus, and Khaya senegalensis were collected in Area BZ of the main campus of Ahmadu Bello University (ABU), Zaria $\left(11^{\circ} 9^{\prime} 48.21048^{\prime \prime} \mathrm{N} 7^{\circ} 38^{\prime} 5.91828^{\prime \prime} \mathrm{E}\right)$. The plants were identified at the Herbarium, Department of Botany, Faculty of Life Science, ABU, Zaria by Namadi Sunusi and the voucher number of each plant was obtained as follow: A. indica-900,151, T. indica- 602, A. leiocarpus- 
1738 and K. senegalensis- 900,181. The collected plant parts were separately dried in the laboratory to a constant weight.

\section{Plant extraction}

Five hundred gram of each of the pulverized plants was extracted with $2.5 \mathrm{~L}$ of absolute methanol using Soxhlet apparatus. Each distilled extract was concentrated to dryness in vacuo using a rotary evaporator. The dried extracts were kept in labeled containers and stored at room temperature in the laboratory until required. The percentage yield of each extract was calculated.

\section{Preliminary phytochemical screening of the extracts}

Phytochemical screening of each extract for the presence of phenolic compounds, alkaloids, anthraquinones and steroids and triterpenes was done on thin-layer chromatography plates (TLC)- silica gel $60 \mathrm{TLC}_{254}$ plate (Merck KGaA, Germany). The plates were sprayed with ferric chloride, Dragendoff's, Bontragers and LiebermannBurchard reagents for phenols, alkaloids, anthraquinones and steroids and triterpenes, respectively.

\section{Experimental animals}

The Wistar rats used for the study were obtained from the Animal Room of the Department of Veterinary Pharmacology and Toxicology, A.B.U., Zaria. Outbred rats were used for the study. The rats were fed rat chow and water was provided ad libitum. The animals were kept in clean iron cages at room temperature throughout the study. The bedding was changed twice weekly throughout the duration of the experiment. Permission for the use of rats was given by the Ethical Committee on Animal Use and Care, Ahmadu Bello University, Zaria (reference number: ABUCAUC/2019/005) and the rats were handled according to its guideline, in line with international best practices for animal experimentation.

\section{Determination of median lethal dose $\left(\mathrm{LD}_{50}\right)$}

Limit dose of $5000 \mathrm{mg} / \mathrm{kg}$ [16] was used to determine the $\mathrm{LD}_{50}$ of each extract.

\section{Acute, sub-acute, sub-chronic and chronic toxicities studies}

Acute, sub-acute, sub-chronic and chronic toxicity studies [17] of the crude methanol extract of each plant were carried out. Twelve nulliparous rats were divided into four groups of 3 rats each. Single oral administration of $5000 \mathrm{mg} / \mathrm{kg}$ of the extract of $A$. leiocarpus was used for acute study (AS) while daily administration of $2000 \mathrm{mg} /$ $\mathrm{kg}$ of the same extract for 2, 12 and 14 weeks was used for sub-acute study (SAS), sub-chronic study (SCS) and chronic study (CS), respectively. Rats in group IV were administered distilled water (negative control, NC). The same procedure was replicated for $A$. indica, $K$. senegalensis, and $T$. indica. All the rats were observed closely for any sign of toxicity within first $6 \mathrm{~h}$ of administration and twice daily: morning (7:00 am) and evening (7:00 $\mathrm{pm})$. A thorough physical examination was carried out at the end of each experiment. Thereafter, the rats were euthanized by jugular venesection. Three milliliters of blood was collected from each rat into a plain sample bottle, allowed to stand on the laboratory bench in an inclined position for $15 \mathrm{~min}$ and then centrifuged at $3000 \times \mathrm{g}$ for $10 \mathrm{~min}$. The resulting serum was transferred into an appropriately labeled Eppendorf tube for serum biochemical evaluations. One milliliter of blood was also collected from each rat into an EDTA bottle for haematology.

\section{Percentage bodyweight changes and organosomatic index (OSI) of liver and kidneys}

The percentage bodyweight change of each rat was obtained by dividing the bodyweight of each rat at the end of the experiment with the bodyweight at the beginning of the experiment and multiplied by $100 \%$. While OSI of liver and kidney of each rat was obtained by dividing the weight of the organ with the weight of that rat at the end of the experiment.

\section{Haematological parameters}

Packed cell volume was determined with hematocrit centrifugation at $3000 \times \mathrm{g}$ for $15 \mathrm{~min}$, total and differential white blood cells were determined by mechanical expansion, optical magnification and supravital cell staining [18].

\section{Liver function test}

Serum levels of transaminases, alkaline phosphatase, total protein, albumin and globulin were determined with AGAPPE $^{\oplus}$ assay kits (Switzerland) according to the manufacturer's instructions.

\section{Kidney function test}

Serum levels of urea, creatinine, $\mathrm{Na}^{+}$and $\mathrm{K}^{+}$were determined with AGAPPE $^{\oplus}$ kits (Switzerland) according to the manufacturer's instructions.

\section{Histology liver and kidney}

After euthanasia, the rats were placed on dorsal recumbency and a midline incision was made on the ventral aspect starting from the base of the neck down to the umbilicus. The liver and the kidneys were carefully exteriorized and cut off and immediately fixed in Bouin's solution. Each sample was dehydrated through a graded series of ethanol and embedded in paraffin. Paraffin sections of the sample were sliced into $5 \mathrm{~mm}$ thickness and mounted onto coated slides. Before staining, sections 
were dewaxed in xylene and rehydrated through a decreasing series of ethanol. The sections were stained with hematoxylin and eosin.

\section{Statistical analysis}

Values obtained were expressed as mean \pm standard error of the mean $( \pm$ SEM), and subjected to two-way analysis of variance followed by Bonferoni post-test for multiple comparisons of the groups. Graph Pad Prism version 5.0 was used. Values of $P<0.05$ were considered statistically significant.

\section{Results}

\section{Percentage yields of the extracts}

The crude methanol extracts of the four plants yielded $17.98 \mathrm{~g}$ (Khaya senegalensis), $18.90 \mathrm{~g}$ (Anogeissus leiocarpus), $34.23 \mathrm{~g}$ (Azadirachta indica) and $31.54 \mathrm{~g}$ (Tamarindus indica).

\section{Preliminary phytochemical screening}

Thin-layered chromatographic screening of the crude methanol extracts of the four plants showed that all the plants contain alkaloids, phenols and steroids and triterpenes. In addition, $K$. senegalensis also contains anthraquinones.

\section{Acute toxicity study}

None of the rats administered extracts of $A$. leiocarpus, $A$. indica and $T$. indica showed any apparent sign of toxicity at the limit dose of $5000 \mathrm{mg} / \mathrm{kg}$ evaluated. However, two rats in the $K$. senegalensis-treated group showed mild lethargy and depression within $24 \mathrm{~h}$ of administration but recovered thereafter and showed no morbidity or mortality throughout the 14-day observation period.

\section{Physical examination}

Generally, no severe physical changes were observed in the rats. However, depression, lethargy, rough and hair coat were observed in the rats administered $K$. senegalensis and A. leiocarpus at $5000 \mathrm{mg} / \mathrm{kg}$ within $24 \mathrm{~h}$ of the administration. Similar signs were observed in the rats administered extract of A. leiocarpus at $2000 \mathrm{mg} / \mathrm{kg}$ during the SA, SC and C studies. However, the animals recovered thereafter.
Percentage bodyweight (PBW) changes and liver and kidney organosomatic index (OSI)

Sub-chronic administration of $A$. leiocarpus and $T$. indica significantly $(P<0.001)$ decreased the percentage weight of rats compared to rats in the NC group (Table 1). Generally, there was no significant increase or decrease in the OSI of liver and kidneys in all the rats treated with extracts of the four plants (Tables 2 and 3).

\section{Liver function test}

Results of toxicological studies on liver function test are shown in Table 4. Single administration of $5000 \mathrm{mg} / \mathrm{kg}$ of $A$. leiocarpus significantly $(P<0.05)$ increased the values of ALP, aspartate aminotransferase (AST) and ALT when compared to the NC. Similarly, A. leiocarpus significantly $(P<0.05)$ increased total protein $(\mathrm{TP})$ in the AS compared to the NC. Paradoxically, administration of $A$. leiocarpus in AS produced significantly $(P<0.05)$ higher values of ALP and AST than SAS, SCS and CS. $A$. indica and $T$. indica produced significantly $(P<0.05)$ higher values of globulin and AST in the CS only compared to the NC. The two plants did not produce any statistically significant changes in all other parameters evaluated. $K$. senegalensis produced significantly $(P<$ 0.05) higher values of ALT in the AS, SAS, SCS and CS compared to the NC. Similarly, K. senegalensis produced significantly $(P<0.05)$ higher values of ALP in the AS, SCS and CS compared to SAS and the NC. Surprisingly, the values of ALT and ALP are significantly $(P<0.05)$ lower in the AS and SCS than in the CS. AST showed significantly higher value in the CS only compared to the SAS and the NC. TP is significantly $(P<0.05)$ lower in the AS than the NC, which is also lower $(P>0.05)$ in the SAS, SCS and CS groups compared to the NC.

\section{Effect of treatments on kidney function test}

Administration of $A$. leiocarpus significantly $(P<0.05)$ increased urea and non-significantly increased $\mathrm{K}^{+}(P>$ 0.05) compared to the NC (Table 5). Surprisingly, administration of $A$. leiocarpus in AS produced significantly $(P<0.05)$ higher values of urea and creatinine than in the SAS, SCS and CS. Administration of 2000 $\mathrm{mg} / \mathrm{kg}$ of $A$. leiocarpus for 14 weeks in the SCS and CS produced significantly higher $\mathrm{Na}^{+}$and $\mathrm{K}^{+}$compared to

Table 1 Effect of short, medium and long term oral administration of extracts of four ethnomedicinal plants in rats on percentage body weight change

\begin{tabular}{llllll}
\hline Type of toxicity study & Anogeissus leiocarpus & Azadirachta indica & Tamarindus indica & Khaya senegalensis & Distilled water \\
\hline Acute & $141.5 \pm 6.64$ & $160.6 \pm 11.88$ & $149.7 \pm 9.53$ & $143.5 \pm 5.19$ & $105.7 \pm 16.34$ \\
Sub-acute & $4.35 \pm 0.46$ & $4.91 \pm 0.30$ & $3.82 \pm 0.84$ & $4.63 \pm 0.37$ & $4.60 \pm 0.80$ \\
Sub-chronic & $14.34 \pm 1.25^{\mathrm{a}^{* *}}$ & $15.84 \pm 1.05$ & $14.04 \pm 2.06^{\mathrm{a}^{* *}}$ & $16.20 \pm 1.41$ & $19.08 \pm 0.70^{\mathrm{b}}$ \\
Chronic & $18.95 \pm 1.39$ & $18.12 \pm 1.05$ & $19.16 \pm 1.13$ & $19.48 \pm 0.52$ & $21.32 \pm 0.87^{\mathrm{b}}$ \\
\hline
\end{tabular}

Keys: ${ }^{*}=0.05 ;{ }^{* *}=0.001$. Different superscripts indicate significant difference 
Table 2 Organosomatic index of liver of rats subjected to short, medium and long term oral administration of extracts of four ethnomedicinal plants

\begin{tabular}{llllll}
\hline Type of toxicity study & AL & Al & TI & KS & DW \\
\hline Acute & $2.876 \pm 0.100$ & $2.489 \pm 0.328$ & $2.835 \pm 0.493$ & $3.053 \pm 0.481$ & $3.923 \pm 0.584$ \\
Sub-acute & $3.241 \pm 0.235$ & $3.756 \pm 0.343$ & $3.285 \pm 0.528$ & $3.686 \pm 0.250$ & $3.247 \pm 0.584$ \\
Sub-chronic & $3.661 \pm 0.492$ & $2.913 \pm 0.329$ & $3.226 \pm 0.575$ & $3.337 \pm 0.210$ & $3.294 \pm 0.584$ \\
Chronic & $3.370 \pm 0.217$ & $2.848 \pm 0.344$ & $3.088 \pm 0.256$ & $2.890 \pm 0.413$ & $3.227 \pm 0.584$ \\
\hline
\end{tabular}

AL Anogeissus leiocarpus, Al Azadirachta indica, TI Tamarindus indica, KS Khaya senegalensis, DW Distilled water

the NC; while AS and SAS yielded significantly $(P<0.05)$ lower $\mathrm{Na}^{+}$and $\mathrm{K}^{+}$, respectively. The results of administration of $K$. senegalensis show that urea and creatinine had significantly $(P<0.05)$ higher values in the AS, SAS, SCS and CS compared to the NC. SAS produced significantly $(P<0.05)$ lower urea compared to the SCS and CS values. $\mathrm{Na}^{+}$is significantly higher only in the CS than the NC. SAS showed significantly $(P<0.05)$ lower $\mathrm{Na}^{+}$ than in the CS. $K$. senegalensis produced significantly $(P<0.05)$ higher values of $\mathrm{K}^{+}$at in the SCS and CS compared to the AS, SAS and NC.

\section{Effects of treatment on haematological parameters}

Prolonged administration of $K$. senegalensis for 12 weeks significantly $(P<0.05)$ increased haemoglobin concentration compared to the NC (Table 6). Other parameters did not produce significant $(P<0.05)$ increase or decrease in the values compared to the NC.

\section{Histology}

Liver

Administration of extracts of A. leiocarpus and K. senegalensis at $5000 \mathrm{mg} / \mathrm{kg}$ for AS produced degenerative changes in the hepatocytes (Fig. 1: VI). SAS of T. indica also showed degenerative changes in the hepatocytes. Whereas congested occluded sinusoids (Fig. 1: IV) and cellular infiltration (Fig. 1: V); and congestion of central vein (Fig. 1: III) were seen in hepatocytes of rats treated with $K$. senegalensis and A. leiocarpus, respectively, in the SAS; prolonged administration of the two plants in the SCS and CS produced foci necrosis (Fig. 1: VIII) and congestion and necrosis (Fig. 1: VII), respectively. While congestion was seen in the hepatocytes of rats administered extract of T. indica at $2000 \mathrm{mg} / \mathrm{kg}$ in the CS (Fig.
1: III), no any histological changes indicative of pathological changes was seen in the hepatocytes of rats administered A. indica (Fig. 1: II).

\section{Kidney}

While the nephrons of rats administered extract of $A$. leiocarpus in the AS and SAS showed congested blood vessel (Fig. 2: III), SCS and CS groups showed necrosis (Fig. 2: IV). Congestion, necrosis and mononuclear cell infiltrations (Fig. 2: V) were seen in the nephrons of rats treated with extracts of $K$. senegalensis (SCS and CS only). Vacuolation (Fig. 2: II) was seen in the nephron of rats administered extract of $A$. indica in the SCS only.

\section{Discussion}

The apparent lack of morbidity and absence of mortality in the determination of median lethal dose $\left(\mathrm{LD}_{50}\right)$ of the four plants show that their $\mathrm{LD}_{50}$ is exceeds $5000 \mathrm{mg} / \mathrm{kg}$. According to Lorke [19] and Tauheed et al [20], a chemical or drug candidate with an $\mathrm{LD}_{50}$ of $5000 \mathrm{mg} / \mathrm{kg}$ or greater is acutely safe and can be used for therapeutic purposes. The apparent safety level recorded in the present study underscores non-safety dose optimisation usage of medicinal plants in folkloric medicine. This agrees with the finding of Tauheed et al [20], who observed that the use of a wide range of doses of decoction and infusion of medicinal plants in traditional medicine could be due to their wide margin of safety.

Bodyweight changes and organo-somatic index (OSI) have been used to predict the toxic effects of exogenous compounds [21]. Because of the importance of the liver and kidneys in drug metabolism and excretion, ratiometric differences of these organs were compared with the bodyweights of treated rats. The significantly lower

Table 3 Effects of short, medium and long term oral administration of extracts of four ethnomedicinal plants in rats on kidney organosomatic index

\begin{tabular}{llllll}
\hline Type of toxicity study & AL & Al & TI & KS & DW \\
\hline Acute & $0.351 \pm 0.024$ & $0.263 \pm 0.037$ & $0.338 \pm 0.038$ & $0.363 \pm 0.034$ & $0.446 \pm 0.035$ \\
Sub-acute & $0.335 \pm 0.041$ & $0.356 \pm 0.031$ & $0.309 \pm 0.029$ & $0.402 \pm 0.0177$ & $0.369 \pm 0.035$ \\
Sub-chronic & $0.386 \pm 0.022$ & $0.314 \pm 0.022$ & $0.351 \pm 0.054$ & $0.433 \pm 0.024$ & $0.375 \pm 0.035$ \\
Chronic & $0.401 \pm 0.037$ & $0.261 \pm 0.043$ & $0.382 \pm 0.035$ & $0.361 \pm 0.027$ & $0.367 \pm 0.035$ \\
\hline
\end{tabular}

AL Anogeissus leiocarpus, Al Azadirachta indica, TI Tamarindus indica, KS, Khaya senegalensis, DW Distilled water 
Table 4 Liver function test of rats subjected to short, medium and long term oral administration of extracts of four ethnomedicinal plants

\begin{tabular}{|c|c|c|c|c|c|c|c|}
\hline Group & Type of toxicity study & ALT (U/I) & AST (U/I) & ALP (U/I) & $\mathrm{TP}(\mathrm{g} / \mathrm{dL})$ & Albumin $(\mathrm{g} / \mathrm{dL})$ & Globulin (g/dL) \\
\hline \multirow[t]{4}{*}{ Anogeissus leiocarpus } & Acute & $52.57 \pm 1.38^{\mathrm{a}}$ & $69.69 \pm 2.56^{a}$ & $157.8 \pm 3.25^{\mathrm{a}}$ & $7.58 \pm 0.15^{\mathrm{a}}$ & $4.18 \pm 0.12$ & $4.03 \pm 0.21$ \\
\hline & Sub-acute & $41.36 \pm 1.53^{b}$ & $53.01 \pm 5.36^{\mathrm{b}}$ & $126.6 \pm 3.50^{\mathrm{b}}$ & $10.17 \pm 0.45^{\mathrm{b}}$ & $4.71 \pm 0.39$ & $4.06 \pm 0.09$ \\
\hline & Sub-chronic & $43.85 \pm 2.08$ & $48.74 \pm 1.20^{\mathrm{b}}$ & $127.1 \pm 3.30^{\mathrm{b}}$ & $9.83 \pm 0.30^{\mathrm{b}}$ & $6.82 \pm 0.15$ & $4.36 \pm 0.12$ \\
\hline & Chronic & $43.72 \pm 3.34$ & $50.69 \pm 0.86^{b}$ & $125.7 \pm 5.21^{b}$ & $9.7 \pm 0.43^{b}$ & $4.55 \pm 0.14$ & $4.23 \pm 0.43$ \\
\hline \multirow[t]{4}{*}{ Azadirachta indica } & Acute & $43.27 \pm 2.68$ & $54.97 \pm 5.17$ & $128.2 \pm 3.85$ & $10.28 \pm 0.14$ & $5.37 \pm 0.09$ & $4.64 \pm 0.22$ \\
\hline & Sub-acute & $40.8 \pm 4.63$ & $50.18 \pm 4.28$ & $125.2 \pm 6.19$ & $9.89 \pm 0.30$ & $4.87 \pm 0.08$ & $3.96 \pm 0.18^{b}$ \\
\hline & Sub-chronic & $40.94 \pm 3.48$ & $49.33 \pm 1.84$ & $128.4 \pm 1.98$ & $9.84 \pm 0.44$ & $5.29 \pm 0.1$ & $4.41 \pm 0.19$ \\
\hline & Chronic & $42.04 \pm 4.01$ & $55.78 \pm 4.28$ & $125.7 \pm 4.90$ & $9.89 \pm 0.25$ & $5.09 \pm 0.22$ & $5.02 \pm 0.22^{\mathrm{a}}$ \\
\hline \multirow[t]{4}{*}{ Tamarindus indica } & Acute & $40.1 \pm 2.93$ & $50.73 \pm 1.3 .82$ & $123.94 \pm 5.43$ & $8.66 \pm 0.26$ & $4.84 \pm 0.14$ & $4.36 \pm 0.21$ \\
\hline & Sub-acute & $42.31 \pm 3.74$ & $47.51 \pm 4.90$ & $129.11 \pm 5.10$ & $9.93 \pm 0.41$ & $5.91 \pm 0.12$ & $4.82 \pm 0.25$ \\
\hline & Sub-chronic & $46.97 \pm 7.09$ & $56.9 \pm 3.83$ & $126.9 \pm 1.95$ & $10.91 \pm 0.27$ & $6.01 \pm 0.45$ & $5.41 \pm 0.41$ \\
\hline & Chronic & $37.94 \pm 4.11$ & $61.22 \pm 5.71^{a}$ & $130 \pm 3.74$ & $10.33 \pm 0.35$ & $5.77 \pm 0.35$ & $5.05 \pm 0.27$ \\
\hline \multirow[t]{4}{*}{ Khaya senegalensis } & Acute & $57.87 \pm 3.38^{\mathrm{a}, \mathrm{x}}$ & $55.66 \pm 4.24$ & $152.9 \pm 3.52^{\mathrm{a}, \mathrm{x}}$ & $7.57 \pm 0.14^{a}$ & $3.94 \pm 0.24$ & $3.96 \pm 0.14$ \\
\hline & Sub-acute & $54.95 \pm 3.35^{a, x}$ & $49.81 \pm 3.82^{b}$ & $125 \pm 5.55^{\mathrm{b}}$ & $8.36 \pm 0.23$ & $4.12 \pm 0.37$ & $4.29 \pm 0.26$ \\
\hline & Sub-chronic & $64.06 \pm 2.39^{a}$ & $57.01 \pm 4.54$ & $156.6 \pm 4.14^{\mathrm{a}, \mathrm{x}}$ & $8.03 \pm 0.45$ & $4.02 \pm 0.20$ & $3.56 \pm 0.30^{\mathrm{a}}$ \\
\hline & Chronic & $70.25 \pm 2.84^{a, y}$ & $68.64 \pm 1.57^{\mathrm{a}}$ & $191.7 \pm 2.99^{\mathrm{a}, y}$ & $8.06 \pm 0.27$ & $4.4 \pm 0.49$ & $4.2 \pm 0.12$ \\
\hline Distilled water & & $39.53 \pm 2.73^{b}$ & $49.31 \pm 3.79^{b}$ & $126.3 \pm 2.42^{\mathrm{b}}$ & $10.06 \pm 0.19^{b}$ & $5.25 \pm 0.14$ & $4.72 \pm 0.17$ \\
\hline
\end{tabular}

$\mathrm{a}$ and $\mathrm{b}=$ significant difference between each group and control (distilled water) group; while $\mathrm{x}$ and $\mathrm{y}=$ significant different within each group

Table 5 Effects of prolonged oral administration of extracts of four ethnomedicinal plants in rats on kidney function assay

\begin{tabular}{|c|c|c|c|c|c|}
\hline Group & Type of toxicity study & Urea (mmol/L) & Creatinine & $\mathrm{Na}^{+}(\mathrm{mmol} / \mathrm{L})$ & $\mathrm{K}^{+}(\mathrm{mmol} / \mathrm{L})$ \\
\hline \multirow[t]{4}{*}{ Anogeissus leiocarpus } & Acute & $5 \pm 0.23^{\mathrm{a}}$ & $22.43 \pm 0.59^{\mathrm{a}, \mathrm{x}}$ & $135.2 \pm 0.60$ & $4.47 \pm 0.09^{x}$ \\
\hline & Sub-acute & $4.27 \pm 0.19^{b, x}$ & $13.71 \pm 0.15^{b, x}$ & $133.7 \pm 0.52^{x}$ & $4.66 \pm 0.10^{x}$ \\
\hline & Sub-chronic & $5.29 \pm 0.22^{\mathrm{a}, \mathrm{y}}$ & $56.76 \pm 0.63^{a, y}$ & $136.9 \pm 0.28^{\text {a.y }}$ & $5.167 \pm 0.15^{\mathrm{a}}$ \\
\hline & Chronic & $5.71 \pm 0.10^{a, y}$ & $57.11 \pm 0.65^{\text {a.y }}$ & $137 \pm 0.18^{\mathrm{a}, y}$ & $5.367 \pm 0.22^{\mathrm{a}, \mathrm{y}}$ \\
\hline \multirow[t]{4}{*}{ Azadirachta indica } & Acute & $3.94 \pm 0.32$ & $14.61 \pm 0.21$ & $134.9 \pm 0.07$ & $4.34 \pm 0.13$ \\
\hline & Sub-acute & $4.04 \pm 0.18$ & $14.24 \pm 0.41$ & $134.8 \pm 0.43$ & $4.407 \pm 0.31$ \\
\hline & Sub-chronic & $4.03 \pm 0.26$ & $14.37 \pm 0.25$ & $134.7 \pm 0.15$ & $4.349 \pm 0.13$ \\
\hline & Chronic & $3.99 \pm 0.23$ & $14.14 \pm 0.54$ & $134.8 \pm 0.28$ & $4.347 \pm 0.1$ \\
\hline \multirow[t]{4}{*}{ Tamarindus indica } & Acute & $3.88 \pm 0.20$ & $15.47 \pm 0.85$ & $139.11 \pm 0.42$ & $4.22 \pm 0.15$ \\
\hline & Sub-acute & $3.62 \pm 0.27$ & $13.68 \pm 0.42$ & $136.49 \pm 0.15$ & $5.07 \pm 0.20$ \\
\hline & Sub-chronic & $4.09 \pm 0.21$ & $14.91 \pm 0.33$ & $136.14 \pm 0.27$ & $4.96 \pm 0.06$ \\
\hline & Chronic & $4.45 \pm 0.33$ & $14.23 \pm 0.35$ & $133.75 \pm 0.35$ & $4.64 \pm 0.21$ \\
\hline \multirow[t]{5}{*}{ Khaya senegalensis } & Acute & $4.65 \pm 0.10^{a}$ & $15.32 \pm 0.07^{\mathrm{a}}$ & $135.3 \pm 0.24$ & $4.7 \pm 0.07^{\times}$ \\
\hline & Sub-acute & $4.37 \pm 0.12^{a, x}$ & $15.18 \pm 0.16^{\mathrm{a}}$ & $134.9 \pm 0.52^{x}$ & $4.72 \pm 0.18^{x}$ \\
\hline & Sub-chronic & $4.63 \pm 0.05^{a, y}$ & $15.55 \pm 0.13^{\mathrm{a}}$ & $135.9 \pm 0.09$ & $5.52 \pm 0.12^{\mathrm{a}, \mathrm{y}}$ \\
\hline & Chronic & $4.74 \pm 0.06^{\mathrm{a}, \mathrm{y}}$ & $15.58 \pm 0.09^{\mathrm{a}}$ & $136.3 \pm 0.17^{a, y}$ & $5.89 \pm 0.12^{a, y}$ \\
\hline & Distilled water & $3.93 \pm 0.05^{b}$ & $14.17 \pm 0.22^{b}$ & $134.8 \pm 0.24^{b}$ & $4.29 \pm 0.16^{b}$ \\
\hline
\end{tabular}


Table 6 Effects of prolonged oral administration of extracts of four ethnomedicinal in rats on blood parameters

\begin{tabular}{|c|c|c|c|c|c|}
\hline Type of toxicity study & $A L$ & Al & $\mathrm{TI}$ & KS & DW \\
\hline \multicolumn{6}{|l|}{ Packed cell volume (\%) } \\
\hline Acute & $41.67 \pm 2.03$ & $39.00 \pm 5.51$ & $33.33 \pm 2.60$ & $44.33 \pm 3.48$ & $41.67 \pm 4.41$ \\
\hline Sub-acute & $40.67 \pm 0.33$ & $37.33 \pm 2.40$ & $39.67 \pm 3.38$ & $44.67 \pm 7.13$ & $40.67 \pm 3.71$ \\
\hline Sub-chronic & $31.00 \pm 0.208$ & $41.33 \pm 2.91$ & $40.00 \pm 1.00$ & $47.67 \pm 6.84$ & $38.67 \pm 2.40$ \\
\hline Chronic & $32.00 \pm 0.346$ & $39.67 \pm 2.03$ & $40.67 \pm 1.76$ & $40.67 \pm 1.76$ & $39.33 \pm 2.91$ \\
\hline \multicolumn{6}{|l|}{ Haemoglobin } \\
\hline Acute & $13.67 \pm 0.88$ & $13.10 \pm 1.73$ & $12.10 \pm 0.59$ & $14.53 \pm 1.35$ & $13.37 \pm 1.77$ \\
\hline Sub-acute & $13.03 \pm 0.26$ & $12.53 \pm 0.87$ & $13.53 \pm 0.79$ & $13.10 \pm 2.62$ & $11.07 \pm 0.52$ \\
\hline Sub-chronic & $10.33 \pm 0.88$ & $13.10 \pm 1.10$ & $12.40 \pm 1.20$ & $16.10 \pm 2.05^{\mathrm{a}^{*}}$ & $11.43 \pm 0.98^{\mathrm{b}}$ \\
\hline Chronic & $9.33 \pm 0.67$ & $11.10 \pm 0.59$ & $12.10 \pm 0.67$ & $11.67 \pm 0.33$ & $11.97 \pm 1.00$ \\
\hline \multicolumn{6}{|c|}{ Total red blood cell count $\left(\times 10^{9} \mathrm{~L}\right)$} \\
\hline Acute & $7.23 \pm 0.15$ & $7.93 \pm 0.58$ & $7.17 \pm 0.44$ & $7.60 \pm 0.57$ & $7.37 \pm 0.71$ \\
\hline Sub-acute & $7.43 \pm 0.28$ & $6.63 \pm 0.86$ & $7.37 \pm 0.35$ & $7.60 \pm 0.90$ & $7.80 \pm 0.42^{b}$ \\
\hline Sub-chronic & $7.60 \pm 0.40$ & $7.20 \pm 0.57$ & $6.93 \pm 0.07$ & $8.50 \pm 0.75$ & $7.60 \pm 0.50$ \\
\hline Chronic & $7.23 \pm 0.50$ & $8.40 \pm 0.64$ & $7.60 \pm 0.50$ & $9.07 \pm 1.02$ & $8.10 \pm 0.78$ \\
\hline \multicolumn{6}{|c|}{ Total white blood cell count } \\
\hline Acute & $10.53 \pm 1.01$ & $13.03 \pm 0.55$ & $7.40 \pm 0.92$ & $11.60 \pm 0.87$ & $9.23 \pm 1.42$ \\
\hline Sub-acute & $9.60 \pm 0.70$ & $7.37 \pm 1.17$ & $10.43 \pm 0.64$ & $9.97 \pm 1.76$ & $10.40 \pm 0.72$ \\
\hline Sub-chronic & $7.13 \pm 2.23$ & $6.97 \pm 2.12$ & $7.63 \pm 2.06$ & $7.57 \pm 1.72$ & $4.97 \pm 0.67^{b}$ \\
\hline Chronic & $5.97 \pm 1.60$ & $8.20 \pm 1.67$ & $6.57 \pm 2.23$ & $8.33 \pm 1.29$ & $10.17 \pm 1.77$ \\
\hline \multicolumn{6}{|l|}{ Neutrophil (\%) } \\
\hline Acute & $19.67 \pm 1.20$ & $29.00 \pm 2.65$ & $34.33 \pm 2.96$ & $26.00 \pm 7.02$ & $33.00 \pm 3.51$ \\
\hline Sub-acute & $23.00 \pm 1.73$ & $38.00 \pm 3.79$ & $30.33 \pm 2.03$ & $26.33 \pm 4.26$ & $33.67 \pm 3.18$ \\
\hline Sub-chronic & $30.67 \pm 2.33$ & $29.33 \pm 3.28$ & $18.33 \pm 2.91$ & $38.00 \pm 4.73$ & $32.33 \pm 1.20$ \\
\hline Chronic & $31.00 \pm 1.00$ & $39.00 \pm 0.00$ & $36.00 \pm 3.79$ & $22.00 \pm 2.08$ & $33.67 \pm 2.91$ \\
\hline \multicolumn{6}{|l|}{ Lymphocyte (\%) } \\
\hline Acute & $66.67 \pm 6.57$ & $67.67 \pm 4.26$ & $55.67 \pm 4.06$ & $65.00 \pm 5.57$ & $53.67 \pm 5.90$ \\
\hline Sub-acute & $65.67 \pm 4.26$ & $52.00 \pm 4.73$ & $48.67 \pm 8.74$ & $53.00 \pm 6.56$ & $49.33 \pm 5.93$ \\
\hline Sub-chronic & $55.33 \pm 6.77$ & $52.67 \pm 4.63$ & $70.33 \pm 9.53$ & $58.67 \pm 4.60$ & $55.67 \pm 6.67$ \\
\hline Chronic & $60.33 \pm 5.93$ & $60.33 \pm 0.33$ & $59.33 \pm 5.78$ & $54.67 \pm 3.18$ & $62.00 \pm 1.53$ \\
\hline \multicolumn{6}{|l|}{ Monocyte (\%) } \\
\hline Acute & $6.00 \pm 1.15$ & $2.00 \pm 1.15$ & $5.33 \pm 1.20$ & $2.33 \pm 0.33$ & $5.67 \pm 1.86$ \\
\hline Sub-acute & $5.33 \pm 3.53$ & $0.00 \pm 0.00$ & $1.33 \pm 1.33$ & $5.33 \pm 1.33$ & $2.00 \pm 1.15$ \\
\hline Sub-chronic & $2.33 \pm 1.86$ & $7.33 \pm 2.40$ & $4.00 \pm 2.00$ & $1.33 \pm 0.88$ & $5.00 \pm 2.08$ \\
\hline Chronic & $5.33 \pm 2.19$ & $0.33 \pm 0.33$ & $3.33 \pm 2.33$ & $6.67 \pm 0.67$ & $3.67 \pm 2.19$ \\
\hline \multicolumn{6}{|l|}{ Eosinophil (\%) } \\
\hline Acute & $0.33 \pm 0.33$ & $0.00 \pm 0.00$ & $0.00 \pm 0.00$ & $0.00 \pm 0.00$ & $0.00 \pm 0.00$ \\
\hline Sub-acute & $1.33 \pm 1.33$ & $2.00 \pm 2.00$ & $0.00 \pm 0.00$ & $0.67 \pm 0.67$ & $0.00 \pm 0.00$ \\
\hline Sub-chronic & $0.00 \pm 0.00$ & $2.33 \pm 1.20$ & $0.33 \pm 0.33$ & $1.00 \pm 0.58$ & $0.00 \pm 0.00$ \\
\hline Chronic & $1.33 \pm 1.33$ & $1.67 \pm 1.20$ & $0.00 \pm 0.00$ & $2.33 \pm 2.33$ & $0.00 \pm 0.00$ \\
\hline \multicolumn{6}{|l|}{ Band neutrophil (\%) } \\
\hline Acute & $0.33 \pm 0.33$ & $0.67 \pm 0.67$ & $1.00 \pm 0.58$ & $0.67 \pm 0.67$ & $1.00 \pm 0.58$ \\
\hline Sub-acute & $0.33 \pm 0.33$ & $0.33 \pm 0.33$ & $0.67 \pm 0.67$ & $4.67 \pm 3.71$ & $1.00 \pm 0.58$ \\
\hline Sub-chronic & $1.33 \pm 1.33$ & $0.67 \pm .33$ & $0.00 \pm 0.00$ & $1.00 \pm 0.58$ & $0.33 \pm 0.33$ \\
\hline
\end{tabular}


Table 6 Effects of prolonged oral administration of extracts of four ethnomedicinal in rats on blood parameters (Continued)

\begin{tabular}{clllll}
\hline Type of toxicity study & AL & Al & TI & KS & DW \\
\hline Chronic & $0.67 \pm 0.67$ & $0.33 \pm 0.33$ & $1.33 \pm 1.33$ & $1.33 \pm 0.33$ & $0.67 \pm 0.67$ \\
\hline AL Anogissu
\end{tabular}

AL Anogeissus leiocarpus, Al Azadirachta indica, TI Tamarindus indica, KS Khaya senegalensis, DW Distilled water. Superscripts: a and b indicate significant difference; $P<0.05^{*}$ and $P<0.001^{* *}$
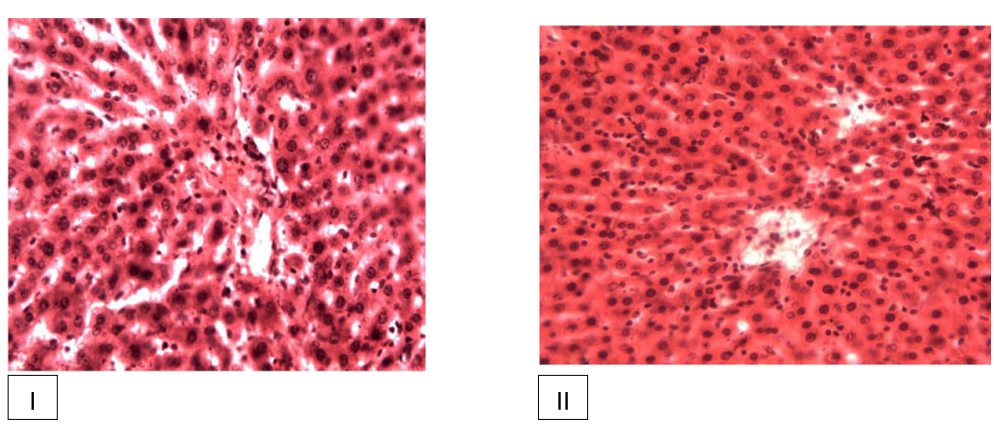

II
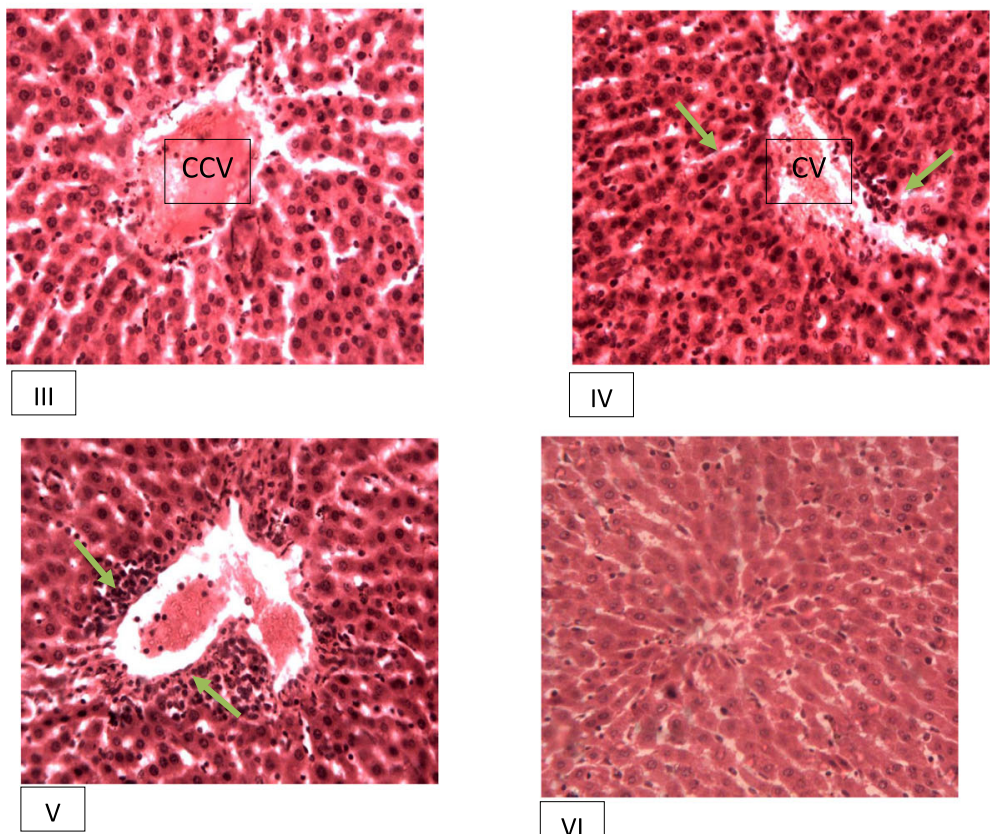

$$
\text { IV }
$$
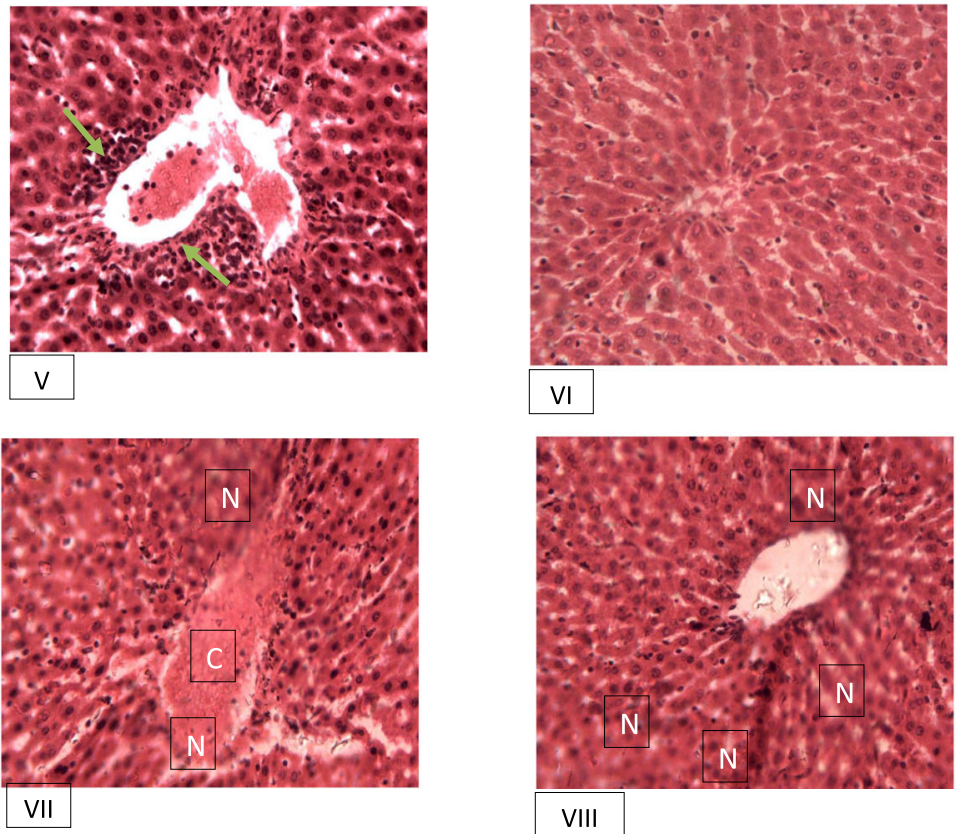

Fig. 1 Histological sections of liver showing varying degrees of pathologies. I: rats administered distilled water showing normal hepatocytes. II: hepatocytes of rats treated with extracts of Azadirachta indica showing no pathology. III: congested central vein (CCV); IV: congestion and occluded sinusoids (arrow heads), with no communications with the central vein (CV); V: congestion and mononuclear cell infiltration (arrows); V: degenerative hepatocyte; VII: congestion (C) and necrosis at 12 and $6 \mathrm{O}^{\prime} \mathrm{clock}(\mathrm{N})$ and VIII: foci necrosis (N) 

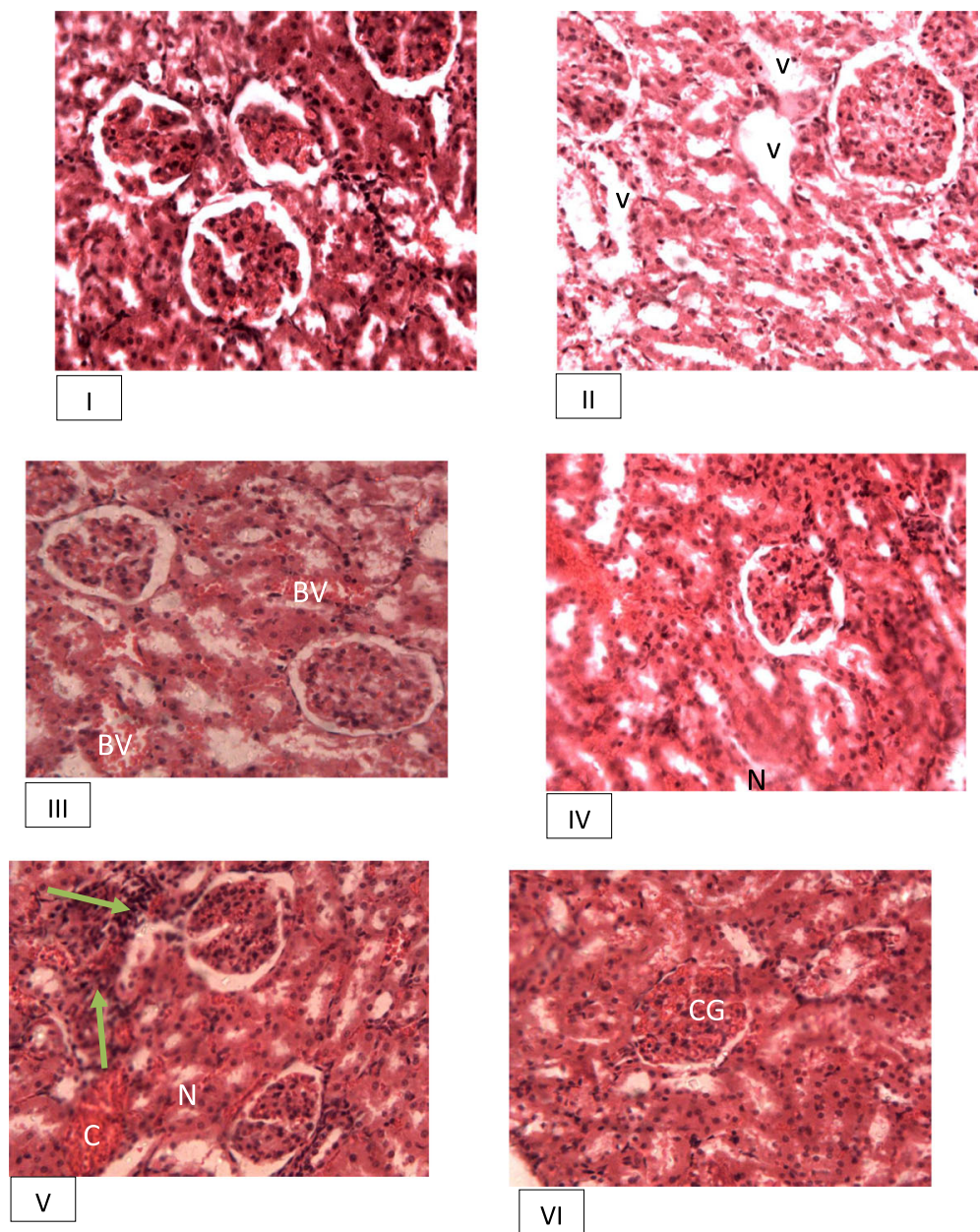

Fig. 2 Kidney histology of the experimental rats. l: rats administered distilled water showing normal kidney histology; ll: vacuolar degenerations (V); III: congested blood vessel (BV); IV: necrosis (N); V: congestion (C), necrosis (N) and mononuclear cell infiltration (arrows); Vl: congested glomerulus (CG)

weight gain observed in the rats treated with $T$. indica may not be due to obvious physiological perturbation since the plant demonstrated protective rather than toxic effects in all the parameters evaluated. The ability of some medicinal plants to decrease weight gain has been used to manage obesity [22]. Although clinical and histological findings from the present study showed varying degrees of toxicity, wet OSI of liver and kidneys did not reveal significant changes. Our results agree with the earlier results of Onu et al. [23] who reported nonsignificant change in the OSI of kidney and heart of rats subjected to sub-chronic administration of $K$. senegalensis and Tantulo and Fotedar [24] who demonstrated no difference in OSI of black tiger prawn juveniles. It follows that significant changes in OSI may occur following extensive insult to the body. OSI may, therefore, not be a sensitive parameter for toxicological studies and its interpretation should be made with caution.
A. leiocarpus and $K$. senegalensis significantly increased serum levels of ALT, AST and ALP at various time intervals, thus, indicating toxic insults to the liver. Unlike AST and ALP which are found in high proportion in other organs and tissues of the body (eg, skeletal muscle, heart, liver, kidney, pancreas and erythrocyte), ALT is predominantly found in the cytosol of hepatocytes and is the most sensitive biomarker of hepatocellular injury used for the assessment of functional integrity of the liver or otherwise toxic insult to the liver [7]. Higher values of aminotransferases (ALT and AST) recorded in our study may indicate hepatocellular injury, while higher values of ALP show hepatobiliary injury. Leakage of transaminases to the extracellular compartment occurs following damage to the liver which is rapidly detected in the serum. Whereas elevated values of ALT may be seen in enzyme induction in rats [25] and muscle injury, elevated AST often occurs following 
damage to other organs/tissues. However, the magnitude of ALT elevation is often greater than AST when both enzymes are elevated due to liver damage. This has been attributed to the longer half-life of ALT and the binding of a sizable proportion of AST to mitochondria [26]. ALP is the most widely used biomarker of hepatobiliary injury in common preclinical species. Serum ALP levels increase when the patency of the bile duct is reduced and is used in a nonclinical and clinical marker of cholestatic liver injury $[25,27]$. The Aminotransferases play a critical role in amino acid metabolism by retaining amino groups during amino acid degradation for subsequent synthesis of new amino acids [28]. The significantly higher values of the transaminases, especially in the A. leiocarpus-treated group may explain the lower weight gain recorded in this group. High values of aminotransferases in the serum mean that the enzymes are being lost, which negatively affects amino acid synthesis, and, thus promotes muscle wastage and consequently, lowers bodyweight gain. Whereas $K$. senegalensis significantly decreased TP in the acute study only, A. leiocarpus produced a significant reduction in TP in the AS, SAS, SCS and CS. Thus, it may be inferred that A. leiocarpus exhibited a sustained depressant effect on the liver and produces prolonged inhibition of protein synthesis. Low protein levels have been shown to be due to extensive liver damage [29].

The concomitant increase in the levels of urea, creatinine, $\mathrm{Na}^{+}$and $\mathrm{K}^{+}$at various levels of treatment with the plants could be attributable to renal impairment, leading to the inability of the kidneys to regulate the amount of these substances that are excreted from the body. Although even a marked increase in serum urea may not point towards primary renal dysfunction since increased urea excretion is a sequel to increased protein metabolism, a marginal increase in serum creatinine has been reported to have a grave long-term consequence on the survival of the patient [30]. Creatinine is a late indicator of acute renal injury [31] and has been used as one of the primary indicators of acute kidney injury [32].

The plants used in the present study are not haemotoxic since they maintained normal blood parameters in all the studies. The ability of the tested plant extracts to maintain adequate haematological parameters may account for their apparent wide margin of safety and thus, maybe the reason why preparations made from these plants, and perhaps other medicinal plants, are used freely.

Histological examination of tissues and organs is used to corroborate physical and clinical findings and aids definitive diagnosis. The observed histopathological lesions, ranging from nonlethal changes (eg, degeneration, congestion) to lethal changes (eg, necrosis) indicate some levels of toxic insults to the chief metabolizing and detoxifying (liver) and excretory (kidneys) organs in the body. Whereas degenerative changes often indicate nonlethal injuries to cells, necrosis indicates terminal, lethal injury to cells [33]. Our findings showed that acute studies produced predominantly degenerative changes in the hepatocytes. This implies that acute studies are associated with mild, reversible damage to the liver in the form of cellular degeneration, which corroborates our clinical findings. We reported significantly higher values of aminotransferases, particularly, ALT; a liver-specific enzyme. Clinical and histopathological findings in this study further revealed salient insult to the liver which is often missed during routine acute toxicity study in the determination of median lethal dose. In routine $\mathrm{LD}_{50}$ determination, animals are dosed once and observed for 14-day before they are sacrificed for clinical and histological examinations. Indeed, mild insults like the transient elevation of aminotransferases in the serum and congestion and degenerative changes in the histological section might have resolved during the 2-week observation period and no obvious lesions may be seen on day 14. Nonetheless, routine $\mathrm{LD}_{50}$ determination is still useful since only a fraction of the $\mathrm{LD}_{50}$ is used for therapeutic evaluation. This is the reason why several authors have reported earlier that compounds with $L_{50}$ of $5000 \mathrm{mg} / \mathrm{kg}$ is acutely safe $[19,20,34]$ and the recommendation by the WHO that such compounds can be used for therapeutic studies [35]. Furthermore, we observed that intermediate and prolonged administrations for 2 and 12-14 weeks, respectively, are associated with lethal cellular injuries in the form of necrosis and fibrosis.

Only $K$. senegalensis showed a nephrotoxic effect. It is possible that $K$. senegalensis is concentrated in the renal tubules and thus provokes a cellular response in the form of congestion, cellular infiltration and necrosis.

\section{Conclusion}

We conclude that Anogeissus leiocarpus, Khaya senegalensis, Azadirachta indica and Tamarindus indica (and perhaps, other medicinal plants) are not devoid of toxic effects, especially when large doses are used. The obvious lack of morbidity and mortality does not rule out pathology but because rats are not immediately sacrificed (eg, keeping animals for 14 days) after administration (single dose in the case of acute toxicity study) or last administration (for continuous dosing in the case of long-term studies) of plant extract(s) or pharmaceutical agents, the transient rise in the traditional biomarkers of liver (transaminases and other enzymes) and kidney function tests are reversible and might have resolved before the animals were sacrificed. Single large dose administration in short-term use produces greater reversible toxic effects on important organs of 
metabolism and excretion than one-quarter of the same dose used over a prolonged period of medium- (4 weeks) and long-term (12-14 weeks) uses. The ability of these plant extracts to maintain adequate hematological parameters, bodyweight and absence of mortality may be responsible for free usage of preparations made from these plants in folkloric medicine. Finally, the study showed that $A$. leiocarpuss and $K$. senegalensis are more toxic than $A$. india and T. indica.

\section{Abbreviations}

ALP: Alkaline phosphatase; ALT: Alanine aminotransferase; AS: Acute study; AST: Aspartate aminotransferase; CS: Chronic study; NC: Negative control; OSI: Organosomatic index; SAS: Sub-acute study; SCS: Sub-chronic study; TP: Total protein

\section{Acknowledgements}

The authors thank Messrs. Dennis Otie, AbdulWahab Hashim, Yusuf Oniwapele and Abdulrazak Sani for their assistance in the harvesting and weighing of the organs and other technical assistance. We appreciate Mr. Sanusi Musa for his assistance in the weighing and dosing of the rats and general care of the experimental animals.

\section{Authors' contributions}

AMT: Conceptualization, design, resources, analysis, investigation and original draft of the manuscript; MM and EOB: design, validation, supervision and proof-read the manuscript; AA: design, validation and supervision; NAS: Investigation and proof-read the manuscript; MMS: design and proof-read the manuscript; MHS: histological sections and interpretations and proof-read the manuscript. The author(s) read and approved the final manuscript.

\section{Funding}

Not applicable.

\section{Availability of data and materials}

The datasets used and/or analysed during the current study are available from the corresponding author on reasonable request.

\section{Ethics approval and consent to participate}

Permission for the use of rats was given by the Ethical Committee on Animal Use and Care, Ahmadu Bello University, Zaria (reference number: ABUCAUC/ 2019/005).

\section{Consent for publication}

Not applicable.

\section{Competing interests}

The authors declare that they have no competing interests.

\section{Author details}

'Department of Veterinary Pharmacology and Toxicology, Faculty of Veterinary Medicine, Ahmadu Bello University, Zaria, Kaduna State, Nigeria. ${ }^{2}$ Africa Centre of Excellence for Neglected Tropical Diseases and Forensic Biotechnology (ACENTDFB), Ahmadu Bello University, Zaria, Nigeria. ${ }^{3}$ Department of Pharmacognosy and Drug Development, Faculty of Pharmaceutical Sciences, Ahmadu Bello University, Zaria, Kaduna State, Nigeria. ${ }^{4}$ Department of Veterinary Physiology and Biochemistry, Faculty of Veterinary Medicine, Bayero University, Kano, Nigeria. ${ }^{5}$ Department of Veterinary Anatomy, Faculty of Veterinary Medicine, Ahmadu Bello University, Zaria, Kaduna State, Nigeria. ${ }^{6}$ Department of Biochemistry, Faculty of Life Sciences, Ahmadu Bello University, Zaria, Kaduna State, Nigeria.

Received: 28 September 2020 Accepted: 23 December 2020 Published online: 02 January 2021

\section{References}

1. Newman DJ, Cragg GM. Natural products as sources of new drugs from 1981 to 2014. J Nat Prod. 2016;79:629-61.
2. World Health Organisation. Traditional medicine strategy: 2014-2023. http:// www.who.int/medicines/publications/traditional/trm_strategy14_23/en/. 2013. Accessed 10 May 2020 at 11:51AM GMT.

3. Harvey AL, Edrada-Ebel R, Quinn RJ. The re-emergence of natural products for drug discovery in the genomics era. Nat Rev Drug Disc. 2015;14:111-29.

4. Thomford NE, Senthebane DA, Rowe A, Munro D, Seele P, Maroyi A, et al. Natural products for drug discovery in the 21st century : innovations for novel drug discovery. Int J Mol Sci. 2018;19:1578-607.

5. Schnellman R. Toxic responses of the kidney. In: Klaassen CD, editor. Casarett and Doull's toxicology: the basic science of poisons. New York: McGraw-Hill; 2008. p. 235-72.

6. Weiler S, Merz M, Kullak-Ublick GA. Drug-induced liver injury: The dawn of biomarkers. F1000 Prime Reports. 2015;7:34.

7. Aulbach AD, Amuzie CJ. Biomarkers in nonclinical drug development. In: Faqi AS, editor. A comprehensive guide to toxicology in nonclinical drug development. London: Academic Press, Elsevier; 2017. p. 447-71.

8. Boone L, Meyer D, Cusick P, Ennulat D, Bolliger AP, Everds N, et al. Selection and interpretation of clinical pathology indicators of hepatic injury in preclinical studies. Vet Clin Pathol. 2005;34:182-8. https://doi.org/10.1111/j. 1939-165x.2005.tb00041.x.

9. Dieterle F, Sistare F, Goodsaid F, Papaluca M, Ozer J, Webb C, et al. 2010. Renal biomarker qualification submission: a dialog between the FDA-EMEA and predictive safety testing consortium. Nat Biotechnol. 2010;28:455-62. https://doi.org/10.1038/nbt.1625.

10. Bhadoriya SS, Ganeshpurkar A, Narwaria J, Rai G, Jain AP. Tamarindus indica: extent of explored potential. Pharm Rev. 2011;5:73-81.

11. Singh D, Baghel US, Gautam A, Baghel DS, Yadav D, Malik J, et al. The genus Anogeissus: a review on ethnopharmacology, phytochemistry and pharmacology. J Ethnopharmacol. 2016;194:30-56.

12. Takin MC, Attindehou S, Sezan A, Attakpa SE, Baba-Moussa L. Bioactivity, therapeutic utility and toxicological risks of Khaya senegalensis. Indian J Pharmaceut Biol Res. 2013;1:122-9.

13. Tiwari R, Verma AK, Chakraborty S, Dhama K, Singh SV. Neem (Azadirachta indica) and its potential for safeguarding health of animals and humans: a review. J Biol Sci. 2014;14:110-23.

14. Weng JK, Philippe RN, Noel JP. The rise of chemodiversity in plants. Sci. 2012;336:1667-70

15. Tauheed AM, Mamman M, Ahmed A, Suleiman MM, Balogun EO. In vitro and in vivo antitrypanosomal efficacy of combination therapy of Anogeissus leiocarpus, Khaya senegalensis and potash. J Ethnopharmcol. 2020;258: 112805 https://doi.org/10.1016/j.jep.2020.112805.

16. Organisation for Economic Co-operation and Development. OECD guidelines for the testing of chemicals. OECD/OCDE. 2008;425:1-27.

17. Aleksunes LM, Eaton DK. Principles of toxicology. In: Klaassen CD, editor. Casarett and Doull's toxicology: the basic science of poisons. New York: McGraw-Hill Education; 2019. p. 25-64.

18. Bain BJ, Bates I, Laffan MA, Lewis SM. Dacie and Lewis practical hematology. 12th ed. Edinburgh: Churchill Livingstone; 2016.

19. Lorke DA. New approach to practical acute toxicity testing. Arch Toxicol. 1983;54:275-87.

20. Tauheed AM, Shittu SH, Suleiman MM, Habibu B, Kawu MU, Kobo PI, et al. In vivo ameliorative effects of methanol leaf extract of Lawsonia inermis Linn on experimental Trypanosoma congolense infection in Wistar rats. Int J Vet Sci Med. 2016;4:33-40.

21. Peters JM, Boyd EM. Organ weights and water levels of the rat following reduced food intake. J Nut. 1966;90:354-60.

22. Buchholz T, Melzig MF. Medicinal plants traditionally used for treatment of obesity and diabetes mellitus - screening for pancreatic lipase and aamylase inhibition. Phytother Res. 2016;30:260-6.

23. Onu A, Saidu Y, Ladan MJ, Bilbis LS, Aliero AA, Sahabi SM. Effect of aqueous stem bark extract of Khaya senegalensis on some biochemical, haematological, and histopathological parameters of rats. J Toxicol. 2013:1-9.

24. Tantulo U, Fotedar R. Comparison of growth, osmoregulatory capacity, ionic regulation and organosomatic indices of black tiger prawn (Penaeus monodon Fabricius, 1798) juveniles reared in potassium fortified inland saline water and ocean water at different salinities. Aquaculture. 2006;258: 594-605.

25. Amacher DE, Schomaker SJ, Burkhardt JE. The relationship among enzyme induction, liver weight, and histological change in beagle toxicology studies. Food Chem Toxicol. 2001;39:817-25. https://doi.org/10.1016/s02786915(01)00030-8. 
26. Blair PC, Thompson MB, Wilson RE, Esber HH, Maronpot RR. Correlation of changes in serum analytes and hepatic histopathology in rats exposed to carbon tetrachloride. Toxicol Letters. 1991;55:149-59. https://doi.org/10. 1016/0378-4274(91)90129-t.

27. Meyer DJ, Harvey JW. Hepatobiliary and skeletal muscle enzymes and liver function tests. In: Meyer DJ, Harvey JW, editors. Veterinary laboratory medicine: interpretation and diagnosis. USA: St. Louis MO Saunders; 2004. p. 169-92.

28. Rudat J, Brucher BR, Syldatk C. Transaminases for the synthesis of enantiopure beta-amino acids. AMB Express. 2012;2:2-10.

29. Wada H, Snell EE. Enzymatic transamination of pyridoxamine. II. Crystalline pyridoxamine-pyruvate transaminase. J Biol Chem. 1962;237:133-7.

30. Linder A, Fjell C, Levin A, Walley KR, Russell JA, Boyd JH. Small acute increases in serum creatinine are associated with decreased long-term survival in the critically ill. Am J Resp Critical Care Med. 2014;189:1075-81.

31. Coca SG, Parikh CR. Urinary biomarkers for acute kidney injury: perspectives on translation. Clin J Am Soc Nephrol. 2008:3:481-90.

32. Kidney Disease Improving Global Outcome (KDIGO). Kidney Disease: Improving Global Outcomes Work Group. KDIGO clinical practice guideline for acute kidney injury. 2012. http://www.kidney-international.org. Accessed 10 Dec 2020.

33. Chandrasoma P, Talorr CR. Concise pathology. 2nd ed. Appleton and Lange: Stamford; 1998.

34. Sani NA, Kawu MU, Bako IG, Sulaiman MH. Mammogenic and lactogenic effects of leaf extract and fractions of Launaea taraxacifolia and resveratrol in lactating Wistar rats. Trop J Nat Prod Res. 2020:4:8-13.

35. World Health Organisation. PAN pesticides database. San Francisco: Pesticide Action Network, North America; 2001.

\section{Publisher's Note}

Springer Nature remains neutral with regard to jurisdictional claims in published maps and institutional affiliations.

\section{Submit your manuscript to a SpringerOpen ${ }^{\circ}$ journal and benefit from:}

- Convenient online submission

- Rigorous peer review

- Open access: articles freely available online

- High visibility within the field

- Retaining the copyright to your article

Submit your next manuscript at $\boldsymbol{\nabla}$ springeropen.com 